\title{
Effects of Thermal Erosion and Wear Resistance on AISI H13 Tool Steel by Various Surface Treatments
}

\author{
Shih-Hsien Chang ${ }^{1, *}$, Kuo-Tsung Huang ${ }^{2}$ and Yung-Hsiang Wang ${ }^{1}$ \\ ${ }^{1}$ Department of Materials and Mineral Resources Engineering, National Taipei University of Technology, \\ Taipei 10608, Taiwan, R. O. China \\ ${ }^{2}$ Department of Auto-Mechanics, National Siluo Agricultural Industrial High School, \\ Yunlin County 64841, Taiwan, R. O. China
}

In this study AISI H13 steel was treated with oxynitriding, CrN coating, and CrN coated with oxynitriding to investigate the molten loss for melting A380 aluminum alloy and wear resistance. The experimental results indicate that the minimum melting loss appeared in duplex surface treatments of $\mathrm{CrN}$ coated with oxynitriding after a $3 \mathrm{~h}$ erosive test. Weight loss was only $0.8 \%$; however the untreated specimen was $3.2 \%$. In addition, all specimens following the different surface treatments, showed a higher wear resistance after the wear test. The untreated specimen showed obvious traces of plough cracks. Conversely, other surface treated specimens experienced very shallow wear. This result shows that the wear resistance of AISI H13 can be effectively improved by performing various surface treatments. The lowest coefficient of friction also appeared in the duplex surface treatment of CrN coated with oxynitriding. The average value of frictional coefficient was 0.28 .

[doi:10.2320/matertrans.M2011360]

(Received November 21, 2011; Accepted January 16, 2012; Published March 25, 2012)

Keywords: AISI H13 steel, oxynitriding, CrN coating, weight loss, wear resistance

\section{Introduction}

In the last decade, surface treatments for steel components with the aim of improving their service performance, (for example, thermo-chemical treatments or a combination of PVD processes and thermo-chemical treatments (the duplex process)), have become common practice. ${ }^{1-3)}$ Nowadays, the different surface treatments are related to the improvement of tool steel wear resistance in harsh environments characteristic of the manufacturing process. ${ }^{4,5)}$

The die casting process uses high pressure to inject high temperature molten alloy into a die cavity. During filling, solidification and the die holding stages, the molten aluminum attacks the die steel surface. ${ }^{6)}$ AISI H13 tool steel is normally used for Al die-casting dies, given its good temperature resistance, high hardness, and good resistance to thermal fatigue, erosion and wear. To extend die-casting die life, different thermo-chemical treatments are often applied to the die surface. Our previous study ${ }^{6}$ ) found that oxynitriding specimens could form a passive film, which contributed a better anti-corrosion property during the corrosion test.

In addition, to improve the surface properties of metals and alloys without altering the bulk properties, such as hardness, corrosion, oxidation and wear resistance, varieties of metal ions with adjustable ion flux and energy can be implanted. ${ }^{7,8)}$ Previous literature ${ }^{9)}$ indicates that surface treatments of the as-deposited $\mathrm{CrN}$ coating with implantation of metal and/or carbon ions result in densification and phase transformation at a near-surface regime. The wear resistance, corrosion resistance and fatigue strength are significantly improved.

Normally in the die casting process, molten aluminum alloy at temperatures ranging from $670-710^{\circ} \mathrm{C}$ is injected into the die cavity at high velocity from $30-100 \mathrm{~ms}^{-1}$. The injection pressure is $50-80 \mathrm{MPa} .^{10,11)}$ Moreover, aluminum die casting tools are exposed to erosion, corrosion and

*Corresponding author, E-mail: changsh@ntut.edu.tw soldering; they are under frequent contact with a tool surface on the casting alloy, and are subject to oxidation due to high pouring temperatures. In this investigation, we aim to clarify the effect of the different surface treatments and combinations on the tool life of AISI H13 through the analysis of XRD, microstructural features, melting loss and wear resistance.

\section{Experimental}

AISI H13 steel was chosen as the substrate material to achieve a homogeneous heat treatment (quenched at $1030^{\circ} \mathrm{C}$ and tempered at $580^{\circ} \mathrm{C}$ for $3 \mathrm{~h}$ and repeated 3 times to reach a hardness of $47 \pm 1 \mathrm{HRC}$ ). The specimens were subjected to various surface treatments including oxynitriding, $\mathrm{CrN}$ coating, and $\mathrm{CrN}$ coated with oxynitriding. The oxynitriding specimens were nitrided for $1 \mathrm{~h}$ at $530^{\circ} \mathrm{C}$ and oxidized via steam for $0.5 \mathrm{~h}$ at $525^{\circ} \mathrm{C}$. CrN coated specimens use the PVD technology for deposition of materials onto the substrates (pre-heating to $430^{\circ} \mathrm{C}$, evaporating the $\mathrm{Cr}$ target and making the vapor ionized, increasing temperature to $500^{\circ} \mathrm{C}$, adding $\mathrm{N}_{2}$ gas under $0.8 \times 10^{-1} \mathrm{~Pa}$ and continuing for $1 \mathrm{~h}$, then depositing the $\mathrm{CrN}$ films). $\mathrm{CrN}$ coated with oxynitriding specimens, which were treated with oxynitriding and then $\mathrm{CrN}$ coating (same as the abovementioned). The chemical compositions of AISI H13 steel are listed in Table 1. In this study, the untreated AISI H13 specimens are designated as "H13" (base metal) hereafter, and the oxynitriding specimens, $\mathrm{CrN}$ coated specimens, and $\mathrm{CrN}$ coated with oxynitriding specimens will be designated as "O-H13", "CrN-H13" and "O-CrN-H13", respectively.

Table 1 Chemical composition of the AISI H13 samples (mass\%).

\begin{tabular}{cccccccccc}
\hline & $\mathrm{C}$ & $\mathrm{Si}$ & $\mathrm{Mn}$ & $\mathrm{Ni}$ & $\mathrm{Cr}$ & $\mathrm{Mo}$ & $\mathrm{V}$ & $\mathrm{Cu}$ & $\mathrm{Fe}$ \\
\hline AISI H13 & 0.34 & 0.81 & 0.38 & 0.14 & 5.00 & 1.15 & 0.67 & 0.11 & Bal. \\
\hline
\end{tabular}


Erosion treated equipment is shown in Fig. 1(a), and the coating specimen size of the erosion test as shown in Fig. 1(b). In this study, an A380 aluminum alloy as a cast material and its composition are listed in Table 2. The erosion resistance of the specimens was evaluated by their weight loss rate (\%): weight loss of the specimens dipped in molten A380 aluminum alloy for a predetermined length of time. The melting solution was maintained at $750^{\circ} \mathrm{C}$, the rotational speeds of the specimens were kept at $100 \mathrm{rpm}$, and the dip time was 3,4 , and $5 \mathrm{~h}$ to evaluate the weight loss rate. After removing the molten alloy, the specimens were cleaned with $\mathrm{NaOH}$ and de-ionized water to remove oxide or other residues. The weight loss rate of the erosion test was calculated as follows: (a)

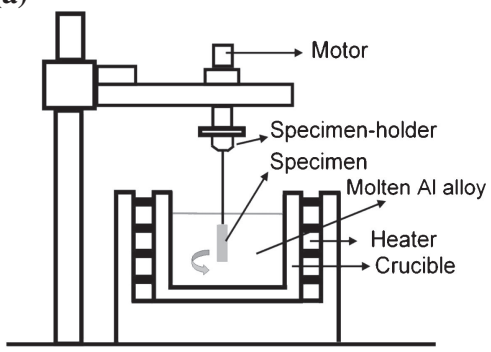

(b)

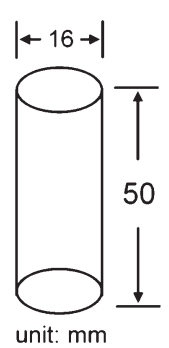

Fig. 1 Schematic illustration of the (a) erosion test setup, (b) specimen dimension of AISI H13 tool steel.

Table 2 Chemical composition of A380 alloy (mass\%).

\begin{tabular}{ccccccc}
\hline & $\mathrm{Si}$ & $\mathrm{Cu}$ & $\mathrm{Zn}$ & $\mathrm{Fe}$ & $\mathrm{Mg}$ & $\mathrm{Al}$ \\
\hline $\mathrm{A} 380$ & 11.22 & 1.62 & 0.78 & 0.86 & 0.3 & Bal. \\
\hline
\end{tabular}

$$
\text { Weight loss rate }(\%)=(\mathrm{IW}-\mathrm{AW}) / \mathrm{IW} \times 100
$$

where, IW is the initial weight and AW is the weight from the after-erosion test.

The wear resistance of the specimens was evaluated in a ball-on-disk test. The wear parameters are: specimen size is $\phi 36 \times \mathrm{D} 5 \mathrm{~mm}$, diameter of $\mathrm{Cr}$ ball is $6 \mathrm{~mm}$, axial load is $4.9 \mathrm{~N}$, disc rotation is $200 \mathrm{rpm}$, sliding speed is $0.63 \mathrm{~ms}^{-1}$, and total rotation is 5000 revolutions. Finally we compared the coefficient of friction with the fracture feature and found the optimal wear resistance of surface treatments for AISI H13 steel.

\section{Results and Discussion}

The X-ray diffraction patterns of various surface-treated specimens are shown in Fig. 2. Figure 2(a) shows that the diffraction peaks of $\alpha$-Fe (110) and $\alpha$-Fe (200) appear in the H13 specimens. The result confirms that heat-treated $\mathrm{H} 13$ steel is $\alpha$-Fe structure at room temperature. Figure 2(b) shows that the intensity of $\alpha$-Fe decreases and the $\mathrm{Fe}_{3} \mathrm{O}_{4}$ and $\mathrm{Fe}_{4} \mathrm{~N}$ phases appear in $\mathrm{O}-\mathrm{H} 13$ specimens. Figure 2(c) shows the main diffraction peaks of CrN (111), (200), (220), (311), and the small peaks of $\mathrm{Cr}_{2} \mathrm{~N}$ and $\alpha$-Fe are also displayed in the CrN-H13 specimens. Previous study has pointed out ${ }^{12)}$ that the $\mathrm{Cr}$ and $\mathrm{Cr}_{2} \mathrm{~N}$ formed in the plasma assisted thermochemical of surface-treated specimens when the temperature was lower than $500^{\circ} \mathrm{C}$, but $\mathrm{CrN}$ formed when the temperature was higher than $500^{\circ} \mathrm{C}$. In addition, minor volume fractions of the $\mathrm{Cr}_{2} \mathrm{~N}$ nitrides were found in the nitrogen expanded austenite formed at $400^{\circ} \mathrm{C}$. $^{13)}$ Therefore, the diffraction peaks of $\mathrm{Fe}_{3} \mathrm{O}_{4}, \mathrm{CrN}$ and $\alpha$-Fe appear in the (a)

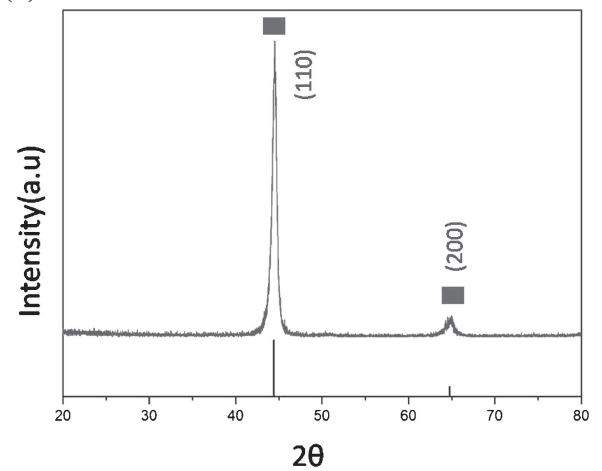

(c)

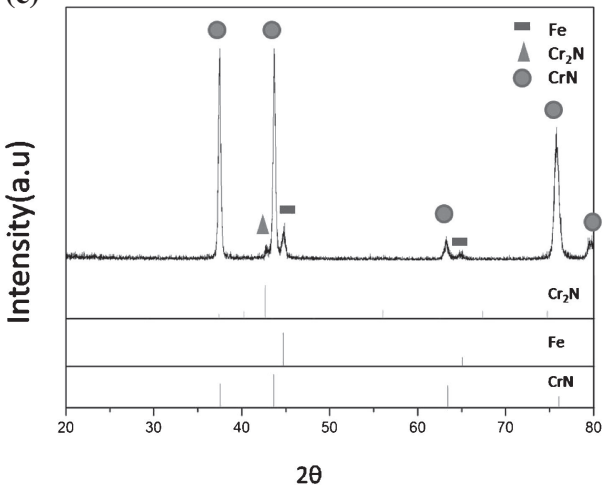

(b)

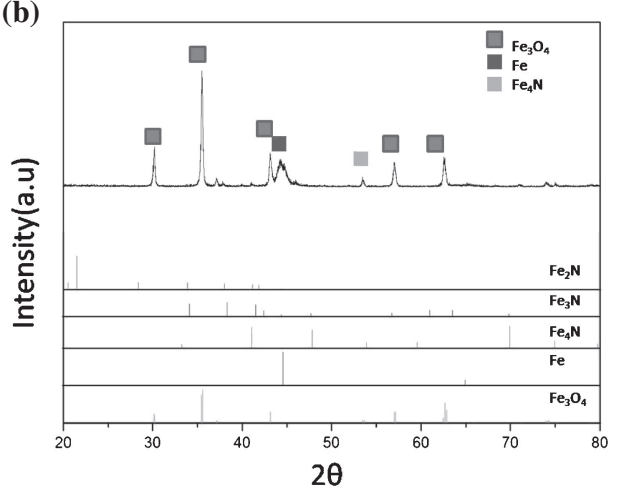

(d)

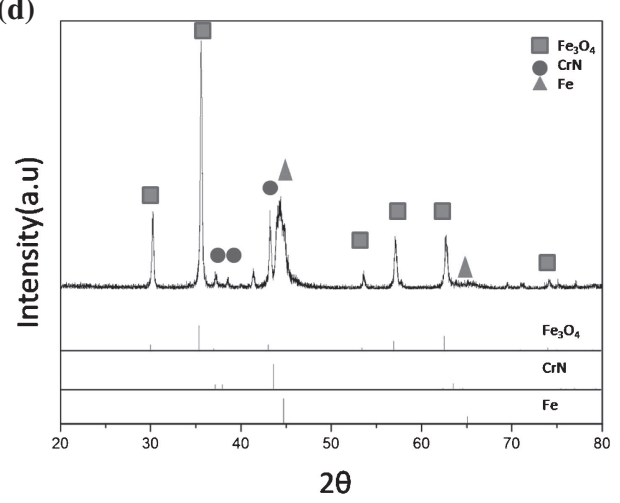

Fig. 2 X-ray diffraction line profiles of the H13, O-H13, CrN-H13 and O-CrN-H13 specimens. 
Table 3 Chemical composition of each location (at $\%)$.

\begin{tabular}{ccccccccc}
\hline Specimen & Area & $\mathrm{Si}$ & $\mathrm{Cr}$ & $\mathrm{Fe}$ & $\mathrm{O}$ & $\mathrm{V}$ & $\mathrm{Ni}$ & $\mathrm{N}$ \\
\hline \multirow{2}{*}{ O-H13 } & $\mathrm{a}$ & - & - & 2.4 & - & - & 97.6 & - \\
& $\mathrm{b}$ & 5.5 & 5.2 & 67.5 & 12.9 & 1.0 & 5.9 & - \\
& $\mathrm{c}$ & - & 5.6 & 91.1 & - & - & - & 3.3 \\
\hline \multirow{2}{*}{ CrN-H13 } & $\mathrm{a}$ & - & 79.1 & - & - & - & - & 29.9 \\
& $\mathrm{~b}$ & - & 6.6 & 92.6 & - & 0.8 & - & - \\
\hline \multirow{2}{*}{ O-CrN-H13 } & $\mathrm{a}$ & - & 32.5 & - & 67.5 & - & - & - \\
& $\mathrm{b}$ & - & 61.8 & - & - & - & - & 38.2 \\
& $\mathrm{c}$ & - & 6.3 & 48.0 & 45.6 & - & - & - \\
& $\mathrm{d}$ & - & 6.4 & 90.2 & - & - & - & 3.4 \\
\hline
\end{tabular}

O-CrN-H13 specimens, but the $\mathrm{Cr}_{2} \mathrm{~N}$ profile peak disappears, as shown in Fig. 2(d).

Microstructure of H13 steel substrate obtained through commercial heat treatment comprises the structure of tempered martensite and proeutectoid carbides. ${ }^{6)}$ Figure 3(a) shows the microstructure of a cross-section of O-H13 specimens where the depth of the oxynitriding layer is about $75 \pm 1 \mu \mathrm{m}$; and the EDS analysis (see Table 3 ) of a, b, and c are the coated Ni layer, Fe oxides, and the nitriding layer, respectively. Due to the outermost layer of gray oxynitriding film is very thin $(1-2 \mu \mathrm{m})$ and hard to find it. Thus in this study, the nickel plating was used for easily observed of oxynitriding layer. Figure 3(b) shows that the SEM image of the CrN treated specimen, and the EDS analysis (see Table 3) of $\mathrm{a}$ and $\mathrm{b}$ are the $\mathrm{CrN}$ compound and substrate (H13) where the thickness of the CrN compound is about $2.5 \mu \mathrm{m}$. Figure 3(c) shows the SEM image of an O-CrN-H13 specimen where the thickness of the oxynitriding and $\mathrm{CrN}$ layer is about $78 \pm 1 \mu \mathrm{m}$, and EDS analysis (see Table 3) of $\mathrm{a}, \mathrm{b}, \mathrm{c}$, and $\mathrm{d}$ are $\mathrm{Cr}$ oxides, $\mathrm{CrN}$ compound, $\mathrm{Cr} / \mathrm{Fe}$ oxides, and substrate, respectively. Due to the ability of $\mathrm{Cr}$ to react easily with $\mathrm{O}_{2}$ to form $\mathrm{Cr}$ oxides, the outer surface is a $\mathrm{Cr} / \mathrm{O}$ compound. Moreover, the $\mathrm{c}$ area is the $\mathrm{Cr} / \mathrm{O} / \mathrm{Fe}$ compound. The Cr element gets $\mathrm{O}_{2}$ from the $\mathrm{Fe}_{3} \mathrm{O}_{4}$ between the $\mathrm{CrN}$ and $\mathrm{Fe}_{3} \mathrm{O}_{4}$ layers, which forms the $\mathrm{Cr} / \mathrm{O}$ compound. Meanwhile the $\mathrm{O}$ ions are also able to diffuse to the outer surface and form a film of $\mathrm{Cr}$ oxides. This explains why the inner portion of $\mathrm{CrN}$ coated specimens (CrN-H13) does not form a film of oxides.

Figure 4 shows the weight loss rate $(\%)$ of various surface treatments. Significantly, the weight loss rate tends to increase as the erosive time increases. In addition, Fig. 4 also indicates that the CrN-H13 and O-CrN-H13 specimens possess the lowest weight loss rate. Due to the high hardness and columnar crystal structure of $\mathrm{CrN}$ coating. ${ }^{14,15)}$ Meanwhile, the CrN layer is very thin $(2.5 \mu \mathrm{m})$ that can easily lead the aluminum solution to penetrate the coating layer, which result in the $\mathrm{CrN}$ specimen with lower corrosion resistance during the shorter corrosion test $(3 \mathrm{~h})$. However, the columnar structure seems to effectively decrease the diffusion time of aluminum and iron elements after a longer corrosion test. In addition, the O-CrN-H13 specimens combine with the high hardness and columnar structure of $\mathrm{CrN}$ coating, and well corrosion resistance of oxynitriding layer. Therefore, the OCrN-H13 specimen has the optimal anti-erosion ability. As a
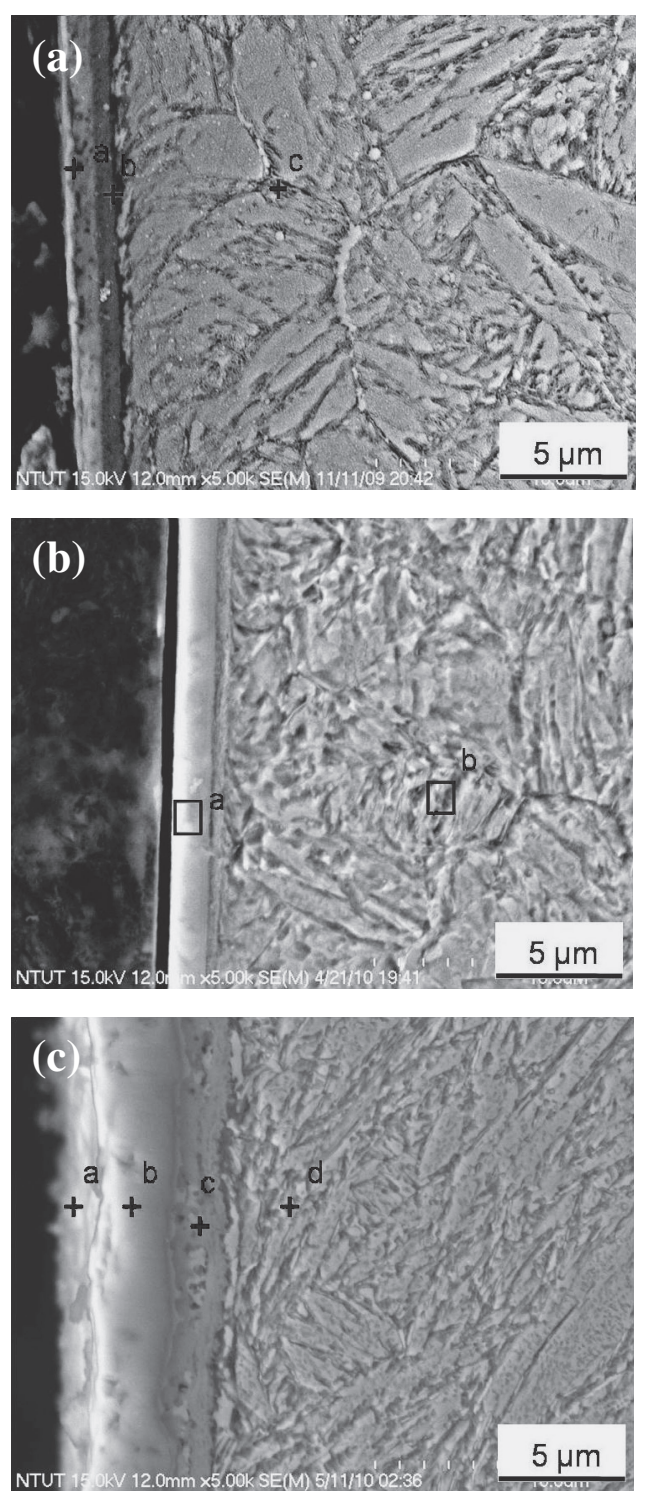

Fig. 3 SEM images of various surface treatments (a) O-H13, (b) $\mathrm{CrN}-\mathrm{H} 13$, (c) O-CrN-H13.

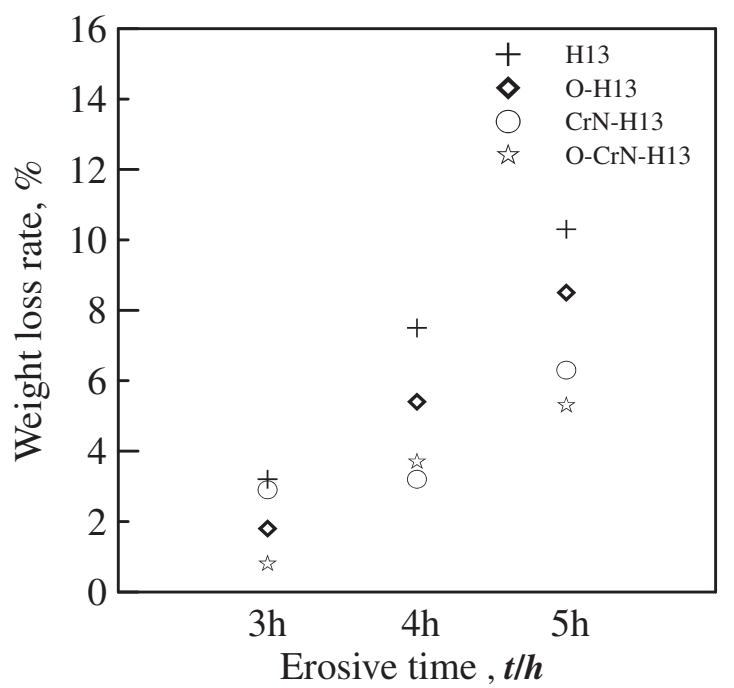

Fig. 4 Weight loss rates of various surface treatments. 

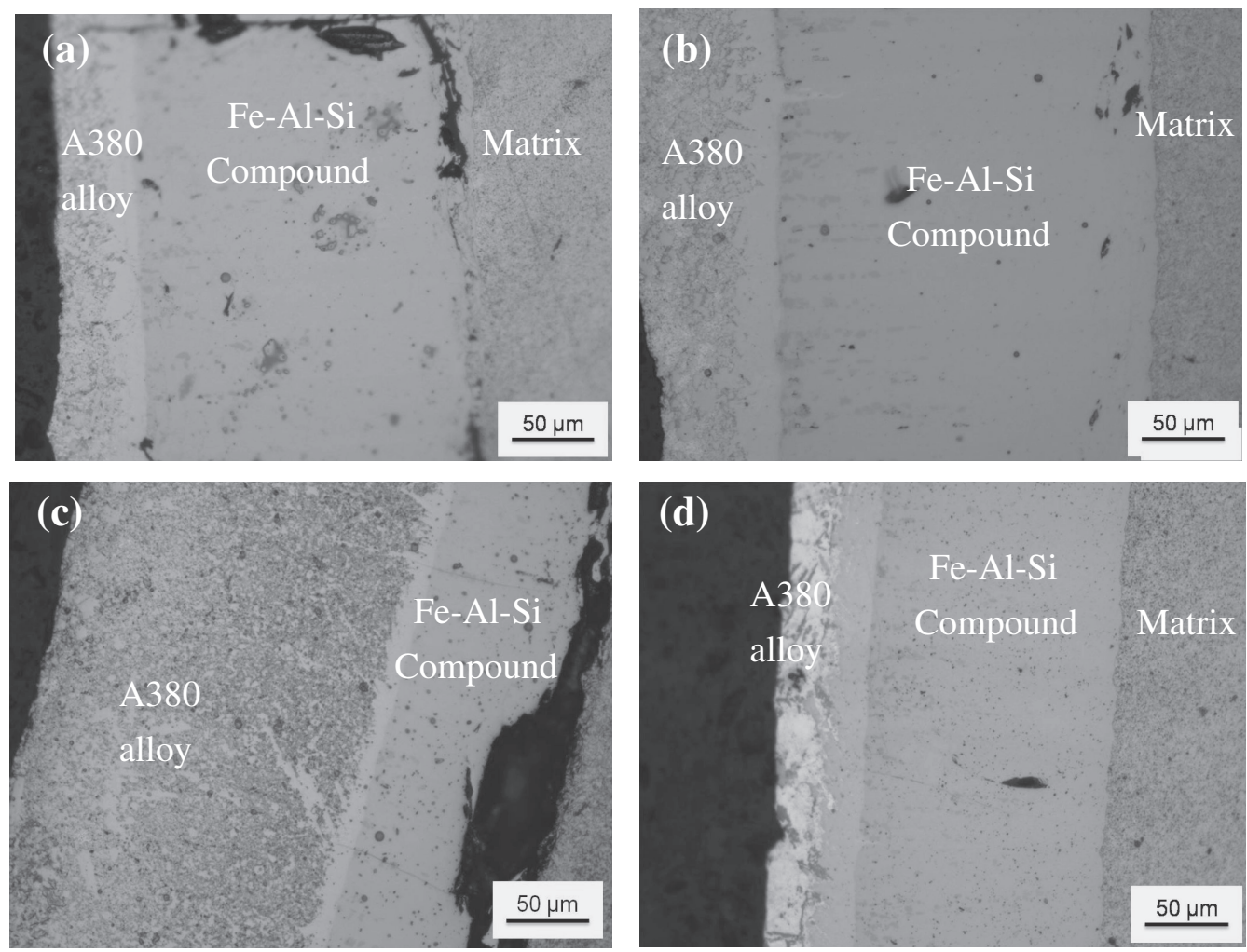

Fig. 5 OM images of various surface treated specimens after 5 h erosion test (a) H13, (b) O-H13, (c) CrN-H13, (d) O-CrN-H13.

result, different surface treatments are effective in improving erosion resistance. Figure 5 shows the optical microstructure of H13, O-H13, CrN-H13, and O-CrN-H13 specimens. The diffusion of $\mathrm{Fe}$ and $\mathrm{Al}$ atoms, which are located between the H13 and A380 alloys, forms the intermetallic compound after $5 \mathrm{~h}$ of erosion testing, as shown in Fig. 5(a). It should be possible for the diffusion of $\mathrm{Al}$ and $\mathrm{Fe}$ atoms across the interface to form a $\mathrm{Fe}-\mathrm{Al}-\mathrm{Si}$ intermetallic at the interface. Moreover, silicon would change the rate of kinetics and the solubility of iron in aluminium. ${ }^{10,11)}$ A slight mass loss takes place on the steel surface. The cyclic process of dissolution continues while the steel surface continuously loses iron in the melting alloy after $5 \mathrm{~h}$ in the erosion test. Figure $5(\mathrm{~b})$ shows the optical microstructure of the O-H13 specimen after a $5 \mathrm{~h}$ erosion test. Notably, the oxynitriding layer disappears after $5 \mathrm{~h}$. This result can further be compared with Fig. 4. The slope of weight loss rate is not significantly different between the $\mathrm{H} 13$ and $\mathrm{O}-\mathrm{H} 13$ specimens after a $4-5 \mathrm{~h}$ erosion test. It is possible to judge that the oxynitriding layer was destroyed after $3-4 \mathrm{~h}$ of erosion test.

Figure 5(c) shows the optical microstructure of a CrN-H13 specimen after a $5 \mathrm{~h}$ erosion test. It was hard to find the coated $\mathrm{CrN}$ layer, which had been destroyed after the $5 \mathrm{~h}$ erosion test. The weight loss of the tested samples could be ascribed to two reasons. One is the diffusion of aluminum entering the matrix, and then, forming a $\mathrm{Fe}_{x} \mathrm{Al}_{y} \mathrm{Si}_{z}$ intermetallic compound in the matrix. Another factor is the $\mathrm{Fe}$ element that escapes from matrix, while combined with aluminum and silicon elements to generate the $\mathrm{Fe}_{x} \mathrm{Al}_{y} \mathrm{Si}_{z}$ compound at the interface during the erosion test processes. ${ }^{6)}$ Significantly, the columnar structure of $\mathrm{CrN}-\mathrm{H} 13$ specimen seems can effectively inhibit the formation of $\mathrm{Fe}_{x} \mathrm{Al}_{y} \mathrm{Si}_{z}$ compound after $4 \mathrm{~h}$ corrosion test. However, it will gradually reduce the corrosion resistance after a longer test $(5 \mathrm{~h})$. A previous study also pointed out ${ }^{16)}$ that the erosive characteristic of $\mathrm{CrN}$ coated specimens is one in which numerous pits appear on the surface. Such appearance may suggest a competition between the corrosion products plugging in the pits. This will be examined in the following paragraph. Figure 5(d) shows the optical microstructure of the O-CrN$\mathrm{H} 13$ specimen after a $5 \mathrm{~h}$ erosion test. It is possible to consider that melting alloy erodes the $\mathrm{CrN}$ coated layer, when eroding pits form on the surface to the inner oxynitriding layer. The result can be further compared with the Fig. 4. Besides, complex oxide layers of $\mathrm{Fe}_{3} \mathrm{O}_{4}$ structures are formed on the matrix's surface after oxidation treatment, which can obviously decrease the weight loss rate. Figure 5(d) confirms that the surface of the O-CrN-H13 specimen had been eroded compared to the H13 specimen [see Fig. 5(a)]. Significantly, compared with the various surface treatments of $\mathrm{H} 13$ specimens, the weight loss rate shows that the O-CrN-H13 specimen is more effectively in improving erosion resistance after longer erosion test $(5 \mathrm{~h})$.

To further examine the intermetallic compound, Fig. 6 and Table 4 show the SEM images and EDS analyses of O-H13, $\mathrm{CrN}-\mathrm{H} 13$, and $\mathrm{O}-\mathrm{CrN}-\mathrm{H} 13$ specimens after a $3 \mathrm{~h}$ erosion test. Table 4 indicates that the alloy compound, in areas b, c, and d for the O-H13 specimen, is almost all $\mathrm{Fe}, \mathrm{Al}$, and $\mathrm{Si}$ elements. Meanwhile, the Fe, Al, and Si layers are about $110 \pm 5 \mu \mathrm{m}$. Though the oxynitriding layer has caused the diffusion of $\mathrm{Fe}, \mathrm{Al}$ and $\mathrm{Si}$ elements; the thicker the oxynitriding layer $(75 \pm 1 \mu \mathrm{m})$ can effectively improving corrosion resistance after $3 \mathrm{~h}$ erosion tests. The distribution of $\mathrm{Fe}, \mathrm{Al}$ and $\mathrm{Si}$ elements, forming the $\mathrm{Fe}-\mathrm{Al}-\mathrm{Si}$ intermetallic 

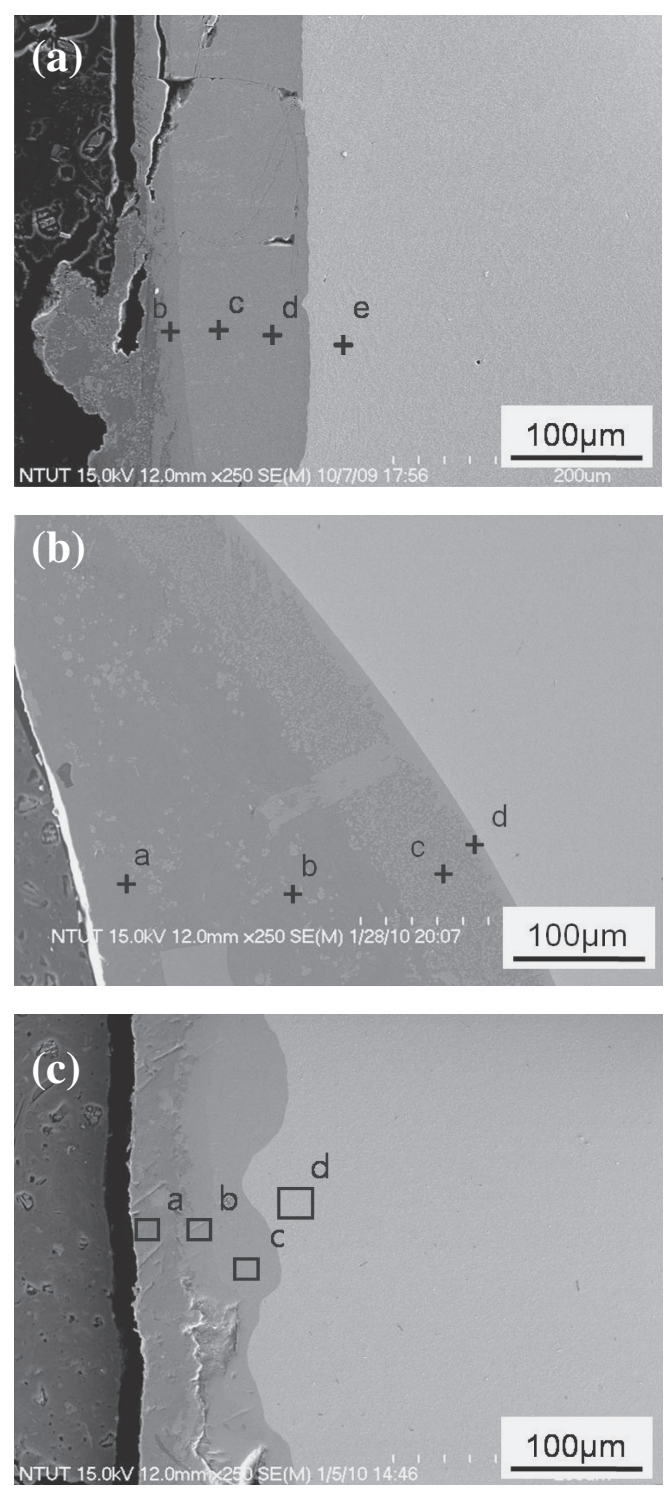

Fig. 6 SEM images of various surface treatments after $3 \mathrm{~h}$ erosion test (a) O-H13, (b) CrN-H13, (c) O-CrN-H13.

compound is verified [see Fig. 6(a)]. The results also agreed with previous studies where the complex intermetallic layers $\mathrm{Al}_{x} \mathrm{Fe}_{y} \mathrm{Si}_{z}$ formed on the surface of the H13 metal could be suggested as $\mathrm{Al}_{4} \mathrm{FeSi}, \mathrm{Al}_{12} \mathrm{Fe}_{6} \mathrm{Si}_{5}$, and $\mathrm{Al}_{15} \mathrm{Fe}_{6} \mathrm{Si}_{5}$. $\left.{ }^{13}\right)$ Furthermore, areas b, c, and d also show the inner Si content as less than the outer one, and the inner Fe content as more than the outer one for the O-H13 specimen. The results could be ascribed to a complex alloy diffusion mechanism.

SEM observations of a cross-section of CrN-NH13 specimens after $3 \mathrm{~h}$ erosion tests are shown in Fig. 6(b). Obviously, the surface of the $\mathrm{CrN}-\mathrm{H} 13$ specimen displays numerous pits of erosion. The EDS analysis shows that A380 alloy appeared in the erosion surface (area: $a, b)$, there are a few $\mathrm{Fe}-\mathrm{Al}-\mathrm{Si}$ compounds formed in the vicinity of the interface (area: c, d), and the outside of the interface has few $\mathrm{Fe}$ solutions. The $\mathrm{Fe}-\mathrm{Al}-\mathrm{Si}$ compounds layers are about $80 \pm 5 \mu \mathrm{m}$, and the $\mathrm{Fe}-\mathrm{Al}-\mathrm{Si}$ compound formed results from a reaction of diffusion between the $\mathrm{A} 380$ alloy and iron substrate at a high temperature $\left(750^{\circ} \mathrm{C}\right)$. The $\mathrm{Fe}$ element escaped from the H13 substrate, which resulted in weight
Table 4 Chemical composition of each location after $3 \mathrm{~h}$ erosion test (at\%).

\begin{tabular}{ccrccccc}
\hline Specimen & Area & \multicolumn{1}{c}{$\mathrm{Si}$} & $\mathrm{Cr}$ & $\mathrm{Fe}$ & $\mathrm{O}$ & $\mathrm{V}$ & $\mathrm{Al}$ \\
\hline \multirow{5}{*}{ O-H13 } & $\mathrm{a}$ & 14.0 & 0.5 & 3.4 & 6.7 & - & 75.5 \\
& $\mathrm{~b}$ & 11.3 & 1.4 & 25.7 & 6.7 & - & 61.6 \\
& $\mathrm{c}$ & 3.8 & 2.2 & 34.0 & - & - & 60.0 \\
& $\mathrm{~d}$ & 1.9 & 3.1 & 34.8 & - & - & 60.2 \\
& $\mathrm{e}$ & 1.6 & 5.4 & 92.1 & - & 0.9 & - \\
\hline \multirow{5}{*}{$\mathrm{CrN}-\mathrm{H} 13$} & $\mathrm{a}$ & 1.6 & - & - & - & - & 98.4 \\
& $\mathrm{~b}$ & 21.8 & - & - & - & - & 78.2 \\
& $\mathrm{c}$ & 6.6 & 1.54 & 8.0 & - & - & 83.8 \\
& $\mathrm{~d}$ & 16.8 & - & 15.5 & - & - & 67.7 \\
\hline \multirow{5}{*}{ O-CrN-H13 } & $\mathrm{a}$ & 7.5 & - & - & 7.1 & - & 85.5 \\
& $\mathrm{~b}$ & 13.4 & 1.6 & 21.1 & - & - & 63.9 \\
& $\mathrm{c}$ & 4.4 & 2.0 & 33.7 & - & - & 59.9 \\
& $\mathrm{~d}$ & 1.8 & 6.0 & 92.0 & - & 1.2 & - \\
\hline
\end{tabular}

loss. Figure 6(b) shows that there are many particles of $\mathrm{Fe}-$ Al-Si compound in the vicinity of the interface. The results agree with the erosive characteristic that the CrN-H13 specimens eroded from numerous pits on the surface, owing to the local breakdown of the $\mathrm{CrN}$ layer. The result can be further compared with the Fig. 3. It shows that the thinner $\mathrm{CrN}$ layer $(2.5 \mu \mathrm{m})$ can easily lead the aluminum solution to penetrate the coating layer, which results in the lower corrosion resistance after $3 \mathrm{~h}$ erosion tests.

Figure 6(c) shows the SEM image of the O-CrN-H13 specimen after a $3 \mathrm{~h}$ erosion test. $\mathrm{Fe}-\mathrm{Al}-\mathrm{Si}$ compound was found between the A380 alloy and substrate, which reveals parts in a wavy appearance. In the alloy layers, two colors appear in the alloy compound. EDS analysis of areas of $a, b$, c, and $d$ in Fig. 6(c) is listed in Table 4. The results can be compared further with Fig. 2(d), where the area of a is A380 alloy, and parts of them have an oxidative phenomenon. The areas of $\mathrm{b}$ and $\mathrm{c}$ are the $\mathrm{Fe}-\mathrm{Al}-\mathrm{Si}$ compounds. The Si content is higher in $\mathrm{b}$ and significantly decreases in c. As a result, the parts of areas depicting the $\mathrm{O}-\mathrm{CrN}-\mathrm{H} 13$ specimen possess a thicker alloy layer due to erosion from pits on the surface. In addition, the thickness of the $\mathrm{Fe}-\mathrm{Al}-\mathrm{Si}$ compound for the OCrN-H13 specimen is less than that in the O-H13 and CrNH13 specimens (about 66-100 $\mu \mathrm{m}$ ). Our previous study ${ }^{6}$ ) found that $\mathrm{Fe}_{x} \mathrm{Al}_{y} \mathrm{Si}_{z}$ compounds could accelerate the erosive rate of AISI 13. Consequently, the O-CrN-H13 specimens can possess better erosive resistance.

Figure 7 shows the coefficient of friction for H13, O-H13, $\mathrm{CrN}-\mathrm{H} 13$, and O-CrN-H13 specimens. The coefficient of friction for the H13 specimen displayed an up and down trend at the beginning of 700-800 cycles, then it obviously increased. Literature pointed out ${ }^{17)}$ that the coefficient of friction going up and down in the initial wearing stage resulted from the surface abrasive particles and oxides of the specimen. Moreover, the coefficient of friction quickly increases between 800-1200 cycles; because the $\mathrm{Cr}$ ball contact with the substrate and the specimens has become worn. Decreasing the coefficient of friction could be ascribed to the oxides appearance on the wearing surface, which produced a lubricating effect for the H13 specimen. The coefficient of friction for O-H13 and CrN-H13 had similar 


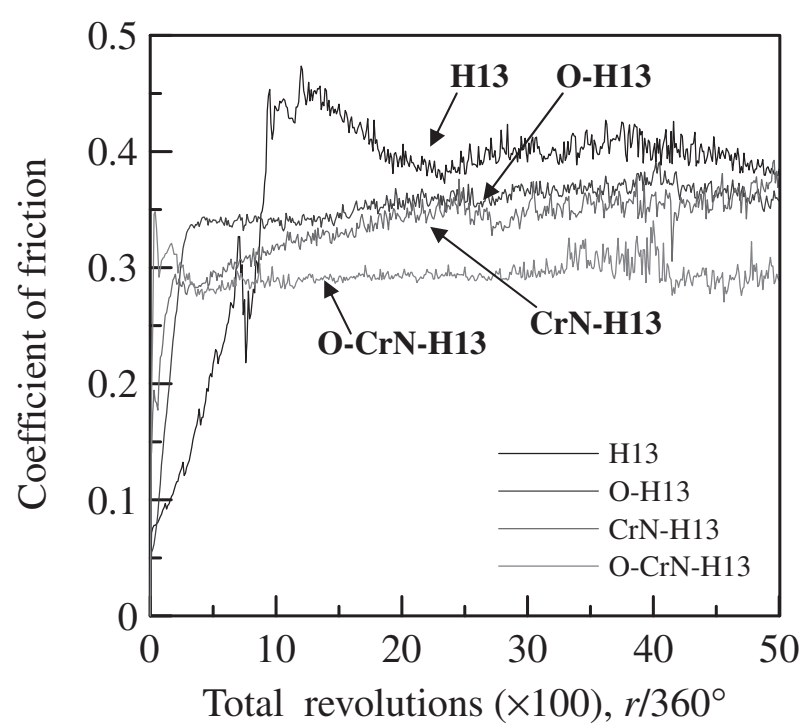

Fig. 7 Comparison the coefficient of friction by different suface treatments.

trends that were maintained at $0.3-0.35$. In addition, the $\mathrm{O}$ CrN-H13 specimen had a slightly high coefficient of friction in the beginning, which decreased, and then stayed at the lowest one. The result can further be compared with Fig. 3 where the higher coefficient of friction $(0.35)$ in the beginning resulted from coated $\mathrm{CrN}$ and $\mathrm{Cr}$ oxides on the surface. The coefficient of friction decreased to 0.3 after the $\mathrm{Cr}$ oxides had been worn away, and then the coefficient of friction $(0.27)$ was constant to the final stage.

As a result, the $\mathrm{O}-\mathrm{CrN}-\mathrm{H} 13$ specimens possess the smallest coefficient of friction. In order to inspect the wear feature of the specimens, Fig. 8 shows the SEM images of H13, O$\mathrm{H} 13, \mathrm{CrN}-\mathrm{H} 13$, and O-CrN-H13 specimens after a wear test. Figure 8(a) shows a lot of traces of abrasive wear and adhesive wear. Literature ${ }^{18)}$ indicates that wearing characteristics of plough cracking, wedge formation, and cutting are the main features of abrasive wear, and some particles producing local bonding from peeling off demonstrate the main feature of adhesive wear. It is reasonable to judge that the H13 specimen experienced abrasive and adhesive wear after the wear test. The EDS analysis shows the sheets of convex are Fe oxides, which resulted from adhesive particles during the wear test. However, it is difficult to judge whether the adhesive particles come from the debris of the $\mathrm{Cr}$ ball or AISI H13. According to the hardness value, the AISI H13 and $\mathrm{Cr}$ ball are $47 \pm 1$ and $60 \pm 1 \mathrm{HRC}$, respectively. As a result, the adhesive particles were affirmed as the debris of substrate.

The O-H13, CrN-H13, and O-CrN13 specimens display traces of abrasive wear on the surface, as shown in Figs. 8(b), $8(\mathrm{c})$ and $8(\mathrm{~d})$. Furthermore, $\mathrm{CrN}-\mathrm{H} 13$ and $\mathrm{O}-\mathrm{CrN}-\mathrm{H} 13$ possess less adhesive particles on the surface. Figure 8(b) shows that there is not significant wear and tear on the surface; instead there are some adhesive particles from the OH13 specimen. On the other hand, the obvious wear and tear appeared on the surface of the Cr ball. The coefficient of friction for O-H13 tends to slightly increase as the cycles of wear testing increases, as shown in Fig. 7, due to $\mathrm{Cr}$ ball wear and tear in the wear test resulting in increasing frictional areas and adhesive particles. Meanwhile, the $\mathrm{CrN}-\mathrm{H} 13$ specimen shows there are few adhesive particles on the surface, and the coefficient of friction is almost constant, as shown in Figs. 8(c) and 7.
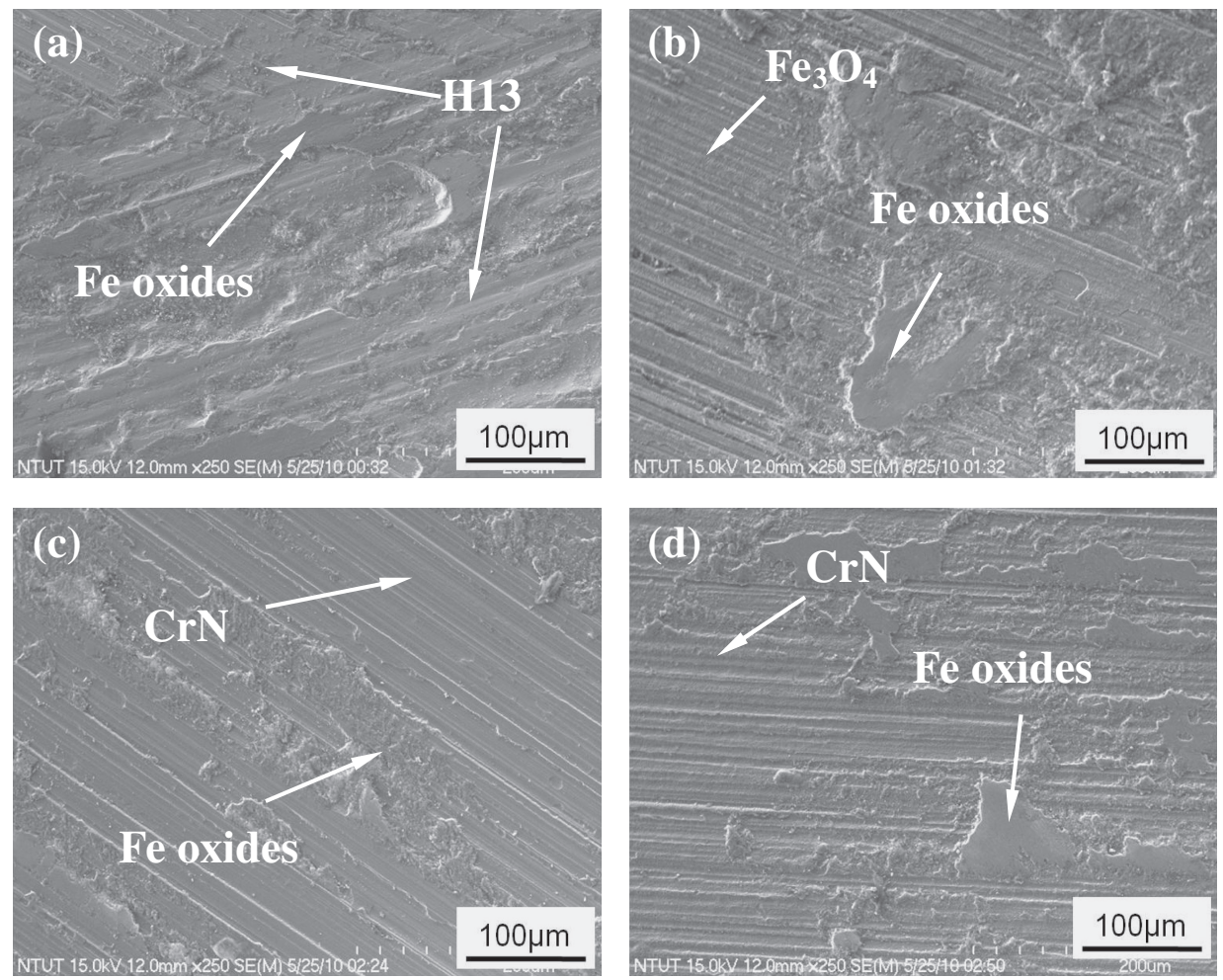

Fig. 8 SEM images of various surface treated specimens after 5000 cycles wear treatment (a) H13, (b) O-H13, (c) CrN-H13, (d) O-CrNH13. 
The EDS analysis shows that the adhesive particles of $\mathrm{O}-\mathrm{H} 13, \mathrm{CrN}-\mathrm{H} 13$, and O-CrN-H13 specimens are Fe oxides. Furthermore, the surface feature of the O-H13, CrN-H13 and O-CrN-H13 specimens showed very shallow traces of wear and tear. The Fe oxide is the debris from the Cr ball resulting from weak bonding after the wear test. Consequently, AISI H13 steel can be effective in improving the wear resistance after different surface treatments. In this study, O-CrN-H13 specimens possess the optimal wear resistance due to the lowest coefficient of friction.

\section{Conclusions}

(1) $\mathrm{Fe}_{3} \mathrm{O}_{4}$ and $\mathrm{Fe}_{4} \mathrm{~N}$ phases have been observed in the oxynitriding specimen. $\mathrm{CrN}$ and weak $\mathrm{Cr}_{2} \mathrm{~N}$ phases are formed on the surface of the $\mathrm{CrN}$ coated specimen. The high intensity of the $\mathrm{Fe}_{3} \mathrm{O}_{4}$ and $\mathrm{CrN}$ phases has been observed in $\mathrm{CrN}$ coated with an oxynitriding specimen.

(2) Compared with the various surface treatments of H13 specimens, the weight loss rate shows that the O-CrNH13 specimen is effective in improving erosion resistance. In addition, the weight loss rate also shows the $\mathrm{CrN}$ coated specimen has a stable ability to guard against the melting A380 alloy.

(3) The wear test result shows that O-CrN-H13 specimens possess the lowest coefficient of friction. In addition, SEM observation shows that only H13 specimens have plough cracks on the surface and other specimens show a very shallow wear and tear on the surface instead of Fe oxides after the wear test. Consequently, the surface treated specimens can effectively improve the wear resistance especially by $\mathrm{O}-\mathrm{CrN}-\mathrm{H} 13$ treatment.

\section{Acknowledgments}

This research supported by the ASSAB STEELS TAIWAN CO., LTD.

\section{REFERENCES}

1) N. Dingremont, E. Bergamnn, M. Hans and P. Collignon: Surf. Coat. Technol. 76-77 (1995) 218-224.

2) N. Dingremont, A. Piannelli, E. Bergmann and H. Michel: Surf. Coat. Technol. 61 (1993) 187-193.

3) S. Liscano, L. Gil, O. A. Leon, M. Cruz and M. H. Staia: Surf. Coat. Technol. 201 (2006) 4419-4423.

4) S. H. Chang, S. C. Lee and T. P. Tang: Mater Trans. 49 (2008) 619623.

5) B. Navinsek, P. Panjan, I. Urankar, P. Cvahte and F. Gorenjak: Surf. Coat. Technol. 142-144 (2001) 1148-1154.

6) S. H. Chang, T. P. Tang and K. T. Huang: ISIJ Int. 50 (2010) 569-573.

7) G. B. Stachowiak, G. W. Stachowiak and P. Evans: Wear 241 (2000) 220-227.

8) S. H. Chang, T. P. Tang, Y. C. Chen and J. K. Chen: ISIJ Int. 49 (2009) $421-424$.

9) D. Y. Wang and K. W. Weng: Surf. Coat. Technol. 156 (2002) 195-200.

10) V. Joshi, A. Srivastava and R. Shivpuri: Wear 256 (2004) 1232-1235.

11) M. Yan and Z. Fan: J. Mater. Sci. 35 (2000) 1661-1667.

12) Nitrex Metal Inc. $\mathrm{ONC}^{\circledR}$ : Superior Wear and Corrosion Resistance Treatment, Québec, Canada, (2000) pp. 1-12.

13) N. Mingolo, A. P. Tschiptschin and C. E. Pinedo: Surf. Coat. Technol. 201 (2006) 4215-4218.

14) D. Y. Wang and M. C. Chiu: Surf. Coat. Technol. 137 (2001) 164-169.

15) C. Y. Su, C. T. Pan, T. P. Liou, P. T. Chen and C. K. Lin: Surf. Coat. Technol. 203 (2008) 657-660.

16) S. Han, J. H. Lin, S. H. Tsai, S. C. Chung, D. Y. Wang, F. H. Lu and H. C. Shin: Surf. Coat. Technol. 133-134 (2000) 460-465.

17) J. L. Mo and M. H. Zhu: Appl. Surf. Sci. 255 (2009) 7627-7634.

18) K. G. Budinski: Surface Engineering for Wear Resistance, (Prentice Hall, New Jersey, 1988) pp. 16-17. 